\title{
Intrahepatic Bile Duct
}

National Cancer Institute

\section{Source}

National Cancer Institute. Intrahepatic Bile Duct. NCI Thesaurus. Code C12677.

The bile ducts which are located within the liver. They include the small interlobular bile ducts, intrahepatic large bile ducts, and the intrahepatic portions of the left and right hepatic ducts. 